\title{
Empreendedorismo: por que alguns estudantes e não outros escolhem ser empreendedores?
}

\section{Entrepreneurship: why do some students and not others choose to become entrepreneurs?}

\section{Mario Duarte Canever*}

Universidade Federal de Pelotas - UFPel, Pelotas, Rio Grande do Sul, Brasil

\section{Volnei Krause Kohls**}

Universidade Federal de Pelotas - UFPel, Pelotas, Rio Grande do Sul, Brasil

\section{Marcelo Lagemann***}

Connectere AgroGestão, Pelotas, Rio Grande do Sul, Brasil

\section{Paulo Rigatto****}

Universidade Federal de Pelotas - UFPel, Pelotas, Rio Grande do Sul, Brasil

\begin{abstract}
RESUMO
O propósito deste artigo foi explorar o interesse dos estudantes universitários no empreendedorismo e as razões que fazem alguns estudantes, e não outros, escolherem ser empreendedores. O estudo foi realizado com 580 estudantes de graduação ( $6 \%$ do total) de seis cursos da Universidade Federal de Pelotas - UFPel/RS através de um survey estruturado. Enquanto os resultados revelam que o interesse em tornar-se empreendedor é alto e mantém-se constante ao longo dos cursos de graduação, somente $6 \%$ dos estudantes planejam de fato tornarem-se empreendedores. Tal decisão é dependente do gênero (homens = mais) e da idade (mais velhos $=$ mais) dos estudantes. Os que planejam empreender são motivados pela independência, são mais atentos ao reconhecimento social, engajam-se mais em atividades fora da universidade, aproveitam o tempo para fazerem várias atividades e acreditam menos que - curso superior lhes oportunizará boa opção salarial. Finalmente, importantes implicações são derivadas para o desenvolvimento de uma educação universitária mais empreendedora.
\end{abstract}

Palavras-chave: Estudantes, Empreendedorismo, Universidade, Habilidades, Motivação.

\footnotetext{
ABSTRACT

The purpose of this research is to examine the entrepreneurial interest of undergraduate students and to explore the reasons why do some students and not others choose become entrepreneurs. The study was realized with 580 students ( $6 \%$ of the total) enrolled in six faculties of Pelotas Federal University in Rio Grande do Sul, Brazil through a structured survey. While the results show that the entrepreneurial interest is high and relatively constant during the whole graduation period, only $6 \%$ of the students plan to start a new business after concluding their studies. This decision is
} 
associated to gender (male $=$ higher) and age (older $=$ higher) of the students. Those who plan to become an entrepreneur are basically motivated by the freedom. They also give more attention to social recognition, to activities outside the university, to the realization of several activities at the same time, and are less confident about the wage opportunities generated by the university degree. The study ends with implications for developing a more entrepreneurial university education.

Key words: Students, Entrepreneurship, University, Abilities, Motivation.

\section{I ntrodução}

O empreendedorismo tem um papel fundamental para o desenvolvimento sócio-econômico, visto que ele é importante para a criação de oportunidades de trabalho, catalisador e incubador do progresso tecnológico e de inovações de produto e de mercado (JACK e ANDERSON, 1999; MUELLER e THOMAN, 2000). Assim, governos estimulam a criação de pequenas e novas empresas no intuito de promover o crescimento econômico e a ampliação da riqueza. Programas bem organizados e estruturados podem facilitar 0 empreendedorismo, e muitas iniciativas para estimulá-lo tem sido realizadas tanto no Brasil (via SEBRAE, por exemplo), quanto em vários outros países (LOUW et al., 2003; GUROL e ATSAN, 2006). Embora se reconheça a importância destes programas, o aparato institucional com maior abrangência e potencial de encorajar o empreendedorismo é o sistema educacional. No Brasil, no entanto, e especificamente em relação ao sistema universitário, têm-se a convicção de que os estudantes são, em geral, educados para ingressarem no mercado de trabalho como empregados e não como empreendedores (DOLABELA, 2005).

A educação empreendedora tem sido reconhecida como um dos fatores cruciais para ajudar os jovens a entenderem e perseguirem uma atitude empreendedora (GORMAN, HANLON e KING, 1997; WANG e WONG, 2004). Em razão da influência que a educação pode ter nas atitudes e aspirações é fundamental que se compreenda como se estimula os jovens a se tornarem empreendedores potenciais ainda enquanto são estudantes nas universidades. Neste estudo, entende-se o empreendedorismo como uma opção de carreira para os egressos dos cursos de graduação.

Existe atualmente uma grande quantidade de atividades no campo da educação empreendedora em universidades ao redor do mundo (GIBB, 1993; JONES e ENGLISH, 2004). Por exemplo, nos Estados Unidos, na Austrália, e em alguns países Africanos e Asiáticos, a quantidade de universidades que oferecem cursos em empreendedorismo tem crescido rapidamente $(\mathrm{KOH}, 1996$; HYTTI e O'GORMAN, 2004). Na Grã Bretanha, chegou-se até a eleger o desenvolvimento do empreendedorismo como uma das quatro metas 
estratégicas para as universidades (KIRBY, 2004). Embora no Brasil não seja razoável afirmar que a educação empreendedora é uma política nacional, cursos em empreendedorismo têm, recentemente, sido oferecidos como disciplinas eletivas, principalmente em faculdades de administração, turismo e informática (LEMOS et al., 2007). Em nível de pós-graduação, também, observa-se algumas iniciativas nos cursos de especialização lato sensu. Contudo, não existe até o momento nenhum curso de graduação e de pósgraduação stricto sensu registrado no Ministério da Educação, especificamente, focado em empreendedorismo. Revisando os sites dos programas de pós-graduação e o banco de teses disponibilizado pela Capes no período de 2005 a $2010^{1}$, encontra-se menos de dez dissertações e teses focadas em empreendedorismo ao nível dos estudantes universitários.

No Brasil, estudos recentes têm aparecido em revistas de várias áreas do conhecimento tratando do empreendedorismo no ambiente acadêmico. Roncon e Munhoz (2009) em um estudo com formandos do curso de enfermagem concluíram que estes possuem baixo grau de características empreendedoras. Sugerem que para o ensino do empreendedorismo se tornar mais eficiente é preciso adotar metodologias próprias, diferentes das adotadas no ensino convencional. Falam de uma abordagem andragógica e fundamentada no "aprender fazendo", que utilize técnicas como oficinas, modelagem, estudos de caso, metáforas e dinâmicas. Concluem que para tal, é também necessário que o professor mude, tornando-se muito mais um incentivador e condutor de atividades do que alguém que dita procedimentos padrões.

Dois outros importantes estudos tratam do empreendedorismo no contexto geral das universidades brasileiras. O primeiro, de Carrer et al., (2010) reflete sobre o atual paradigma da pesquisa científica, da formação de recursos humanos e a importância do ensino do empreendedorismo no âmbito das universidades. O segundo, de Ipiranga, Freitas e Paiva (2010) investigou o empreendedorismo acadêmico no contexto da interação universidade-empresa-governo. Tais estudos fazem importantes reflexões sobre a prática do empreendedorismo na universidade, mas não objetivam investigar as atitudes e motivações dos estudantes nem o interesse destes de se tornarem empreendedores.

O empreendedor de sucesso tem um conjunto de habilidades, características e comportamentos que vão além dos ensinamentos puramente comerciais que são, geralmente, ensinados nos cursos de graduação. São estes atributos, modo de pensar e comportar-se, que precisam ser desenvolvido nos estudantes, quando se quer melhorar suas capacidades empreendedoras (KIRBY, 2004; MITCHELL et al, 2007). Baseado neste argumento pensa-se que seja necessário identificar as mudanças que o meio universitário causa nas 
preferências profissionais futuras dos estudantes, assim como as características, as motivações e comportamentos de parte dos estudantes que fazem do empreendedorismo sua escolha profissional, de modo a influenciar o debate referente à educação universitária empreendedora.

Objetiva-se neste estudo (1) identificar, se o desejo de tornar-se empreendedor muda com o passar dos anos da vida universitária; (2) analisar por que alguns estudantes e não outros escolhem ser empreendedores; e (3) discutir as possíveis implicações deste estudo no desenvolvimento de uma educação universitária empreendedora.

\section{Referencial teórico}

Da mesma forma que "não se ganha jogo sem jogar", ninguém se torna bem sucedido sem desejos. Pesquisas anteriores têm focado nas aspirações futuras dos estudantes universitários e concluído que o desejo de tornar-se empreendedor aumentou nos últimos anos. Nos anos 80, nos Estados Unidos, cerca de $25 \%$ dos estudantes universitários desejavam ser autoempregados (SCOTT e TWOMEY, 1988), enquanto que nos anos 90, tal proporção aumentou para mais de 50\% (TIMMONS, 1994; KOURILKY e WALSTAD, 1998). Contudo, não mais de $5 \%$ dos estudantes preferiam operar seus próprios negócios quando eram levados a considerar suas situações atuais e limitações (BRENNER, PRINGLE e GREENHAUS , 1991). Resultados similares foram encontrados para Grã Bretanha, Noruega, Holanda, Canadá e Singapura (WANG e WONG, 2004), confirmando que o desejo de se tornar autoempregado entre os estudantes é muitas vezes superior a taxa real de autoemprego que, para estes países, é cerca de $10 \%$ da população. Também no Brasil têm-se observado, entre os estudantes, uma crescente atitude em direção ao empreendedorismo. Provinciali et al. (2005) identificaram que mais de $25 \%$ dos estudantes de quatro cursos de Administração de Empresas do estado de Sergipe pretendiam abrir o seu próprio negócio após a conclusão do curso. Já o relatório do $\mathrm{GEM}^{2}$ de 2006 (SCHLEMM et al., 2007 ) mostra que os brasileiros apresentam um dos mais altos níveis de desejo de serem autoempregados entre os mais de 40 países pesquisados. Além disso, no Brasil, o desejo de tornar-se empreendedor mantém-se estável desde o relatório inicial realizado em 2001, mas apenas $2 \%$ dos brasileiros atualmente são autoempregados, o que é pouco em relação a outros países.

Além da propensão ao empreendedorismo, vários fatores que a afetam têm também sido analisados na literatura. Estes se dividem em fatores sociais, ambientais e individuais (SHANE, LOCKE e COLLINS, 2003; GUROL e ATSAN, 2006). Os fatores sociais dizem respeito aos efeitos das características familiares, das experiências ao 
longo da vida e do estágio da carreira dos indivíduos no ímpeto empreededor. Já o modelo dos fatores ambientais concentra-se em analisar o empreendedorismo sob a ótica contextual no que diz respeito aos impactos da redução dos níveis de taxação, das condições do mercado, dos sistemas de suporte, da cultura econômica, das oportunidades ao empreendedorismo, entre outros fatores (ALSTETE, 2002; VAN STEL e STOREY, 2004; AUDRETSCH e KEILBACH, 2004;). Os fatores individuais examinam 0 empreendedorismo sob a perspectiva das ações humanas baseadas em fatores motivacionais e cognitivos (LOCKE, 2000; MITCHEL, et al., 2007). Os principais fatores individuais - motivacionais - estudados são a necessidade de autorealização, a propensão a tomar decisões que envolvem risco, a tolerância a ambiguidade, o locus de controle, entre outras. Os fatores individuais - cognitivos - dizem respeito às habilidades, inteligência e talentos individuais que influenciam no comportamento empreendedor.

Com base nos estudos anteriores, neste artigo, alguns dos fatores sociais, ambientais e individuais que podem exercer influências no desejo dos estudantes tornarem-se empreendedores serão analisados. Parte relevante do trabalho diz respeito à análise dos efeitos do ambiente - estágio no curso de graduação - e dos fatores individuais (tanto motivacionais quanto cognitivos) no desejo em tornar-se empreendedor. Portanto, a primeira noção assumida neste artigo é a de que os indivíduos precisam ser estudados no contexto dos seus ambientes, pois o desejo de tornar-se empreendedor é um processo dinâmico que pode se manifestar nas diferentes etapas da vida estudantil. A segunda noção importante é a de que as ações humanas e, especificamente, o desejo de se tornar empreendedor, pode depender de interações entre os três fatores acima mencionados (fatores sociais, ambientais e individuais). Isso significa dizer, por exemplo, que para isolar os efeitos dos fatores individuais no empreendedorismo, os outros fatores que podem ter relações causais no desejo a empreender precisam ser controlados. Por exemplo, SHANE, LOCKE e COLLINS (2003) sugerem a inclusão de variáveis de controle como as oportunidades do mercado, a disponibilidade de recursos e os aspectos de política governamental de modo a isolar os efeitos dos fatores individuais no empreendedorismo. Similarmente, no âmbito do empreendedorismo universitário variáveis de controle podem ser utilizadas para capturar a variância que é causada pelos fatores ambientais e ou sociais no processo empreendedor. Entre estas podemos citar: o curso que se está realizando, o gênero dos estudantes e o convívio com familiares empreendedores.

Com relação ao gênero, muitos estudos têm focado na sua influência sobre o empreendedorismo, mas ainda não se tem resultados definitivos. Tem-se observado que os estudantes homens têm maior 
aspiração em se tornarem empreendedores do que as estudantes mulheres (MATTHEWS e MOSER, 1996; CRANT, 1996). Tradicionalmente tem-se o autoemprego como domínio dos homens e este fato foi associado à menor propensão das mulheres a tomar decisões que envolvam risco (WANG e WONG, 2004). Entretanto, o autoemprego feminino está aumentando mais rapidamente do que o masculino, o que possivelmente enfraquecerá a associação entre empreendedorismo e masculinidade.

Um segundo fator frequentemente discutido na literatura é a existência de familiares com envolvimento em negócios próprios. Pais com autoemprego influenciam no interesse dos filhos em tornarem-se empreendedores, como também na escolha das suas carreiras. De Wit e Van Winden (1989) explicam que esta influência se dá através de dois modos. Primeiro, é provável que filhos de pais que possuem negócios próprios são mais prováveis de iniciarem seus negócios, pois seguem os exemplos deles (pais como modelos). Segundo, pais com negócios próprios tendem a ter meios econômicos e sociais mais efetivos para suportar as iniciativas empreendedoras dos filhos. Neste sentido, estes autores preconizam uma correlação positiva entre a propensão ao empreendedorismo dos filhos e a renda familiar e o status social da família.

De Wit e Van Winden (1989) e Brown (1990) encontraram que o efeito dos pais serem autoempregados teve um impacto significativo, mas seu status social não, para predizer o autoemprego dos filhos. Entretanto, alguns estudos encontraram resultados contraditórios para estes correlacionamentos. Por exemplo, Brenner, Pringle e Greenhaus (1991) e Ghazali, Ghosh e Tay (1995) não encontraram relação significativa entre os pais terem negócios próprios e as aspirações empreendedoras dos estudantes. Matthews e Moser (1996) encontraram que esta relação só foi significativa para estudantes ainda em curso, mas não para àqueles que haviam terminado seus cursos dois e cinco anos antes.

Entre os fatores individuais - cognitivos - o efeito da educação na propensão ao autoemprego é ambíguo na literatura. Autores como Stewart et al. (1999) identificaram uma relação negativa entre nível de educação e desejo de se tornar empreendedor. Para estes autores tal relação é negativa devido ao fato de que indivíduos com mais conhecimento tendem a ser mais avessos ao risco e então são menos interessados em engajar-se na atividade empreendedora. Outro fator que pode contribuir para que esta relação seja negativa é o custo de oportunidade de maiores níveis de conhecimento, visto que indivíduos com melhores níveis educacionais podem acessar com mais facilidades carreiras lucrativas nas grandes empresas já existentes. Por outro lado, no estudo realizado por Van de Ven e Schroeder (1984) o nível de educação foi positivamente associado com o sucesso na criação de novas empresas. O efeito positivo é mais 
acentuado nos casos de criação de empresas em setores de alta tecnologia. Dolton e Makepeace (1990) identificaram que a taxa de autoemprego não é relacionada com o desempenho escolar, enquanto que Ghazali, Ghosh e Tay (1995) mostraram que estudantes com melhores notas são menos prováveis de se engajarem no autoemprego.

O processo empreendedor ocorre por que as pessoas agem e procuram por oportunidades. A ação humana, no entanto, difere de indivíduo para indivíduo porque cada um tem desejos e habilidades diferenciadas (SHANE, LOCKE e COLLINS, 2003). As variações entre as pessoas, no que concerne a seus desejos e habilidades para agir, tem um efeito considerável no processo empreendedor. Mas como referido anteriormente, o processo empreendedor não é unicamente resultado da ação humana, mas também dos fatores externos (por exemplo, a situação macroeconômica, a disponibilidade de capital, a ação dos competidores, e as regulações governamentais). Contudo, se os fatores ambientais forem mantidos constantes, muitos autores afirmam que os fatores individuais passam a ter um papel crítico no processo empreendedor (LOCKE, 2000; SHANE, LOCKE e COLLINS, 2003; BARON, 2004).

Dentre os fatores individuais - motivacionais - a habilidade/propensão a tomar decisões que envolvem risco é um dos mais estudados. Desde o trabalho pioneiro de McClelland (1961) temse pensado que os indivíduos empreendedores tendem a ser moderadamente propensos a tomar decisões que envolvem riscos porque os empreendedores, frequentemente devem aceitar incertezas com relação ao bem-estar financeiro e psicológico, a segurança de suas carreiras e das relações familiares. Entretanto, pesquisas sugerem que empreendedores não diferem significativamente em relação a executivos e mesmo em relação à população em geral, quanto à propensão ao risco (ver, por exemplo, PALICH e BAGBY, 1995). Outras pesquisas, no entanto, sugerem que de fato os empreendedores têm maiores propensões a decisões de risco, mas não percebem suas ações como arriscadas (FRY, 1993; SARASVATHY, SIMON e LAVE, 1998), porque eles são mais autoconfiantes. Neste sentido, Baum (1994), demonstrou que a autoconfiança é uma característica presente nos indivíduos que realizam tarefas e atingem certo nível de realizações. A autoconfiança é importante para o processo empreendedor visto que este, geralmente, está envolvido por situações ambíguas, o que requer grande esforço, persistência e planejamento dos indivíduos. Cromie (2000) também associou autoconfiança ao empreendedorismo, porém na sua visão, autoconfiança é resultado do empreendedorismo ao invés de ser seu determinante.

Neste estudo não se pretende esgotar as várias dimensões individuais que afetam o processo empreendedor. Portanto, não se trata de uma 
revisão completa destas dimensões, mas apenas ilustram-se aquelas que, de alguma forma, foram exploradas na literatura e que, hipoteticamente, possuem relação com a escolha futura dos estudantes. Além das já apresentadas anteriormente, encontram-se referências na literatura internacional de que os indivíduos e estudantes podem seguir a carreira empreendedora porque desejam independência, autorealização e trabalho apaixonante (SHANE, LOCKE e COLLINS , 2003; GUROL e ATSAN, 2006). Alguns autores também associam o desejo em tornar-se empreendedor com ações deliberadas por parte dos estudantes em direção a melhorias de suas capacidades empreendedoras. Estudantes com pretensões empreendedoras buscam treinamentos, estágios e trabalhos que, normalmente, não são aqueles preferidos pelos demais estudantes (WANG e WONG, 2004).

Ser empreendedor não é uma profissão que certos tipos de pessoas adotam, mas um processo que ocorre ao longo do tempo. Por isto, não se pode considerar o desejo de tornar-se empreendedor apenas no início ou no fim dos cursos de graduação, pois se pode incorrer no erro de rejeitar os efeitos dos fatores externos advindos da experiência universitária. Como bem ilustrado por Lassance (1997), a experiência universitária apresenta pelo menos quatro fases distintas (fase do entusiasmo, fase da decepção, fase do interesse crescente e fase de conclusão) que interferem nas relações aluno-escola e alunodesejos profissionais. Espera-se que o desejo em tornar-se empreendedor e os fatores individuais que interferem neste desejo também sofram mudanças com o passar do tempo na universidade.

\section{Procedimentos metodológicos}

\subsection{A amostra}

A pesquisa (survey) compreende estudantes matriculados em nove semestres dos cursos de engenharia agronômica, medicina veterinária, economia, administração de empresas, nutrição e odontologia da Universidade Federal de Pelotas, no Rio Grande do Sul (Tabela 1). Estes cursos de graduação compreendem as três principais áreas de formação disponibilizadas na universidade. A amostra consistiu de 580 estudantes, que representa $6 \%$ do total dos estudantes de graduação da instituição. A coleta de dados foi feita mediante a realização de entrevistas diretas, nas quais foi preenchido um questionário. A pesquisa de campo ocorreu em fevereiro de 2008 por ocasião da realização das matrículas do primeiro semestre do referido ano, obedecendo a quota de no mínimo cinco (5) estudantes por semestre. 
Tabela 1: Distribuição da amostra

\begin{tabular}{|c|c|c|c|c|c|c|}
\hline \multirow{2}{*}{ Semestre } & \multicolumn{6}{|c|}{ Qrso de graduação } \\
\hline & Agronomia & Veterinária & Economia & Administrạ̃̃o & Nutrị̧̃ $0^{2}$ & Odontologia \\
\hline Primeiro & 16 & 15 & 11 & 9 & 9 & 17 \\
\hline Segundo & 11 & 14 & 0 & 8 & 0 & 15 \\
\hline Terceiro & 14 & 19 & 18 & 9 & 14 & 9 \\
\hline Quarto & 14 & 15 & 0 & 9 & 0 & 16 \\
\hline Quinto & 14 & 13 & 0 & 12 & 13 & 17 \\
\hline Sexto & 19 & 10 & 10 & 13 & 0 & 15 \\
\hline Sétimo & 17 & 17 & 0 & 13 & 12 & 10 \\
\hline Qitavo & 17 & 18 & 8 & 8 & 0 & 12 \\
\hline Nono & 14 & 10 & 0 & 11 & 0 & 15 \\
\hline Total & 136 & 131 & 47 & 92 & 48 & 126 \\
\hline $\begin{array}{l}\text { Amostra / total } \\
\text { de alunos do } \\
\text { curso }\end{array}$ & $23,86 \%$ & $27,69 \%$ & $29,56 \%$ & $35,11 \%$ & $26,37 \%$ & $29,65 \%$ \\
\hline
\end{tabular}

${ }^{a}$ Os cursos de Economia e Nutrição só possuem uma entrada anual. Portanto, alguns semestres são inexistentes nestes cursos.

\subsection{As variáveis}

O instrumento de pesquisa consiste de duas partes. Na primeira, as informações referentes à idade, sexo, local de nascimento, curso de graduação, semestre no curso, tipo de escola (pública ou privada) onde cursou o ensino médio, envolvimento de familiares com negócio próprio e renda familiar mensal (como proxy para o status social e econômico da família) foram coletadas. A parte dois refere-se aos questionamentos do interesse por parte dos entrevistados em tornarem-se empreendedores e aos fatores individuais que perfazem uma personalidade empreendedora. $O$ interesse em tornar-se empreendedor foi medido por uma escala Likert de cinco pontos (variando de 1-nenhum interesse a 5-muito interesse), enquanto que o planejamento para o pós-formatura, considerando a realidade atual de cada estudante, foi medido por uma questão de múltipla escolha (1-continuar estudando, 2-montar o seu próprio negócio, 3-trabalhar no(s) negócio(s) da família, 4-trabalhar como empregado no setor privado, 5-trabalhar como empregado no setor público, 6-combinar mais de uma das alternativas e, 7-não sabe).

As variáveis para medir a importância das motivações dos estudantes em relação à escolha profissional para o pós-formatura foram medidos através de escalas Likert de cinco pontos (variando de 1nada importante a 5-muito importante). Os ítens medidos foram a importância de ser independente, do reconhecimento social, do retorno financeiro, da realização pessoal e da relevância social da carreira futura. Em relação à autoconfiança, os estudantes responderam a duas perguntas também por meio de escala Likert de cinco pontos (variando de 1-não acredita a 5-acredita muito) medindo a crença deles na capacidade de fazer a diferença nas suas carreiras profissionais e na crença de que seus cursos de graduação 
irão oportunizar boa remuneração salarial. A atitude dos estudantes em relação ao risco foi medida por escala Likert de cinco pontos (variando de 1-nada importante a 5-muito importante) para a seguinte frase "O risco de falhar na vida profissional é uma preocupação para você". O conhecimento em empreendedorismo foi medido através de duas questões sobre o autoconhecimento para iniciar um novo negócio e o conhecimento para administrar um negócio (variando de 1-nenhum conhecimento a 5-muito conhecimento).

A atitude dos estudantes quanto ao estudo foi medido através de uma única variável, a qual indica o interesse de serem ótimos alunos. Além desta, uma pergunta de múltipla escolha explicitando as várias opções de treinamento, estágios e trabalhos possíveis de serem realizados ao longo da graduação foi apresentada, para capturar as ações dos estudantes em relação às práticas condizentes com 0 espírito empreendedor. Finalmente, uma última questão refere-se ao nível de satisfação com o curso de graduação. Tal questão também foi medida através de escala Likert de cinco pontos (variando de 1nada satisfeito a 5-muito satisfeito).

\section{Resultados e análises}

Na Tabela 2, apresenta-se o nível de conhecimento e o interesse no empreendedorismo entre os estudantes. O survey mostra que tanto o conhecimento negocial (para iniciar e para administrar um negócio), quanto o interesse dos estudantes em empreender é alto. Cerca de $60 \%$ dos estudantes afirmam que seus conhecimentos para iniciar e para administrar um negócio são razoáveis ou muito bons, e somente $16 \%$ afirmam que possuem nenhum ou pouco conhecimento. Similarmente, seus interesses em iniciar um novo negócio é relativamente alto. Somente $17,9 \%$ dos estudantes têm pouco ou nenhum interesse em empreender, enquanto $57,6 \%$ dos estudantes são razoavelmente interessados ou muito interessados.

Tabela 2: Interesse em empreender e conhecimento para iniciar e administrar um negócio ${ }^{\mathrm{a}}$ 
Mario Duarte Canever, Volnei Krause Kohls, Marcelo Lagemann, Paulo Rigatto Empreendedorismo: por que alguns estudantes e não outros escolhem ser empreendedores?

\begin{tabular}{lccc}
\hline Nivel da descrição & $\begin{array}{c}\text { Nivel de } \\
\text { Interesse em } \\
\text { empreender }\end{array}$ & $\begin{array}{c}\text { Nivel de } \\
\text { conhecimento para } \\
\text { iniciar um novo } \\
\text { negócio }\end{array}$ & $\begin{array}{c}\text { conhecimento para } \\
\text { administrar um } \\
\text { negócio }\end{array}$ \\
\hline Nenhum & $5,8 \%$ & $1,8 \%$ & $1,4 \%$ \\
Pouco & $12,1 \%$ & $15,0 \%$ & $16,2 \%$ \\
Mais ou menos & $24,5 \%$ & $22,5 \%$ & $24,9 \%$ \\
Razoável & $27,8 \%$ & $41,4 \%$ & $36,7 \%$ \\
Muito & $29,8 \%$ & $19,3 \%$ & $20,8 \%$ \\
\hline
\end{tabular}

${ }^{a}$ Amostra válida $=562$

Pondo estes resultados em perspectiva quanto aos cursos de graduação (Tabela 3 ), observa-se que os alunos de economia são os que dizem ter o menor nível de conhecimento para iniciar e gerenciar um negócio, enquanto que os de administração apresentam o maior nível. Em relação ao interesse em empreender, os alunos da nutrição, seguidos pelos da odontologia, são aqueles que apresentam o menor interesse em empreender, enquanto que os da veterinária apresentam o maior nível de interesse. Conhecimentos para administrar um negócio não é conteúdo da maioria dos cursos de graduação, exceto do curso de administração de empresas. Nesse curso, coerentemente com as expectativas, os alunos acreditam ter um nível maior de conhecimentos para administrarem um negócio do que os alunos dos demais cursos.

Tabela 3: Interesse em empreender e conhecimento para iniciar e administrar um negócio por curso de graduação

\begin{tabular}{lccc}
\hline $\begin{array}{c}\text { Curso de } \\
\text { graduação }\end{array}$ & $\begin{array}{c}\text { Nivel de conhecimento } \\
\text { para iniciar }\end{array}$ & Interesse em empreender & $\begin{array}{c}\text { Nivel de conhecimento para } \\
\text { administrar/gerenciar }\end{array}$ \\
\hline Agronomia & 3,62 & 3,68 & 3,57 \\
Veterinária & 3,58 & 3,74 & 3,53 \\
Economia & 3,26 & 3,61 & 3,35 \\
Administração & 3,61 & 3,61 & 3,78 \\
Nutrição & 3,75 & 3,45 & 3,75 \\
Odontologia & 3,71 & 3,60 & 3,58 \\
\hline Média da Amostra & 3,61 & 3,64 & 3,59 \\
\hline
\end{tabular}

Para testar se o interesse em empreender muda conforme 0 passar do tempo na universidade utilizou-se a análise de variância. Embora o interesse em empreender varie entre os semestres (Gráfico $1)$, a diferença entre as médias não é significativa ( $F=0,358, \mathrm{gl}=8$, $565, p>0,05)$. O Gráfico 1 , inclusive, mostra que os estudantes do nono semestre estão entre os que têm o maior nível de interesse em emprender entre todos os semestres. 
Gráfico 1: Interesse em empreender conforme a experiência universitária

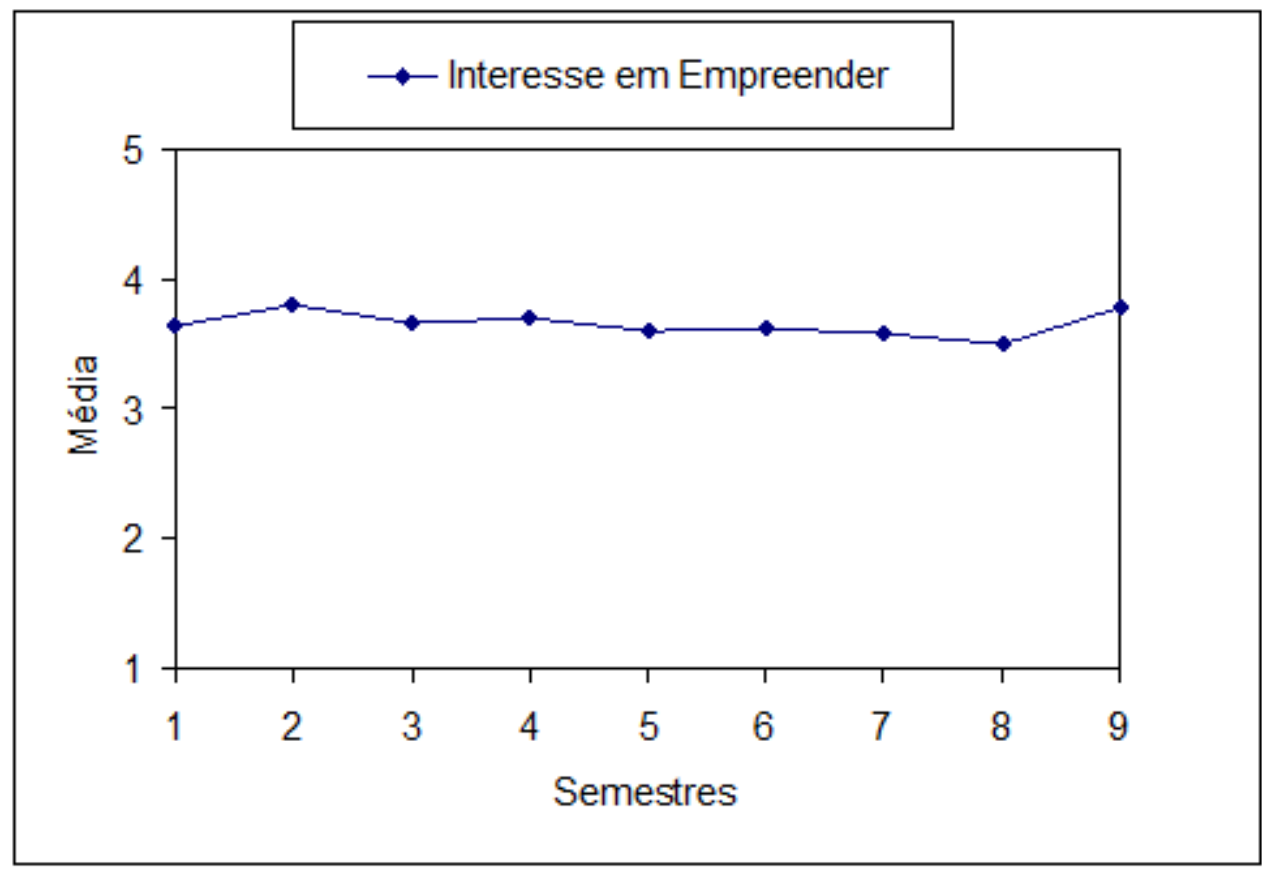

A associação entre o interesse em empreender e as variáveis motivacionais e atitudinais são mostrados na Tabela 4. Ao contrário do esperado, os níveis das correlações são em geral baixos e não significativos e não demostram um padrão uniforme de aumento ou redução conforme os estudantes passam de um semestre para outro. A única variável que se mostrou moderadamente associada com o interesse em empreender foi a crença em ser capaz de fazer a diferença na carreira profissional futura no primeiro e nono semestres $(r=0,30$ e $r=0,46$, significativos a $p=0,01$ e 0,001, respectivamente).

Portanto, os resultados mostram que ao contrário do que se propagam cotidianamente na academia e na mídia, os estudantes não apresentam redução no interesse em empreender da fase inicial para a final dos cursos de graduação. Este mesmo resultado foi também observado quando os dados foram analisados por curso, pois em nenhum dos seis cursos o interesse em empreender diferiu significativamente entre os semestres. Ademais, para o caso específico dos estudantes universitários, observou-se baixa associação entre aquelas variáveis motivacionais e atitudinais estudadas e o interesse em empreender ao longo dos semestres dos cursos de graduação, o que demonstra um descompasso com a teoria sobre empreendedorismo (KIRBY, 2004; BRENNAN e MCGOWAN, 2006; GUROL e ATSAN, 2006), a qual preconiza que motivações, 
desejos e habilidades são fortemente associadas com a decisão de tornar-se empreendedor.

Tabela 4: Correlações entre o interesse em empreender e variáveis motivacionais e atidudinais

\begin{tabular}{|c|c|c|c|c|c|c|c|c|c|}
\hline \multirow{2}{*}{$\begin{array}{l}\text { Variáveis motivacionais = } \\
\text { atitudinais }\end{array}$} & \multicolumn{9}{|c|}{ Semestres } \\
\hline & 10 & $2^{\circ}$ & $3^{\circ}$ & $4^{\circ}$ & $5^{\circ}$ & $6^{\circ}$ & 70 & $8^{\circ}$ & 90 \\
\hline $\begin{array}{l}\text { IndependÊncis "ser dono do proprio } \\
\text { nariz". }\end{array}$ & 0,12 & 0,03 & 0,03 & $0,27^{*}$ & 0,14 & $0,30^{*}$ & 0,14 & 0,03 & 0,13 \\
\hline Reconheximento social / Status & 0,23 & $-0,05$ & $0,27^{*}$ & 0,07 & 0,16 & $-0,14$ & 0,15 & 0,05 & $0,34 *$ \\
\hline Retorno financairo & 0,13 & 0,05 & 0,06 & 0,11 & $-0,14$ & $-0,05$ & 0,21 & $-0,01$ & 0,17 \\
\hline Reslizacaso profissional & 0,12 & 0,08 & 0,06 & 0,10 & 0,09 & $-0,06$ & 0,00 & 0,04 & 0,15 \\
\hline $\begin{array}{l}\text { Relevăncia social (colaborar para a } \\
\text { melhoria da sociedade) }\end{array}$ & 0,20 & $-0,09$ & $-0,13$ & $0,33^{*}$ & 0,14 & $-0,21$ & 0,07 & 0,06 & 0,18 \\
\hline $\begin{array}{l}\text { Acredita ser capaz de fazer a } \\
\text { diferenga na carreira profissional } \\
\text { futura }\end{array}$ & 0,30 wa & 0,05 & $-0,13$ & $-0,02$ & 0,16 & 0,08 & 0,02 & 0,11 & $0,46^{* *}$ \\
\hline $\begin{array}{l}\text { Acredita que o curso the } \\
\text { oportunizará bos opgso salarial }\end{array}$ & 0,20 & 0,05 & $-0,06$ & $-0,16$ & 0,00 & $-0,07$ & 0,01 & 0,06 & 0,14 \\
\hline Risco de falhar na vida profissional & 0,06 & 0,08 & 0,01 & $-0,01$ & $-0,02$ & 0,10 & $-0,02$ & $-0,02$ & 0,06 \\
\hline
\end{tabular}

* correlações significativas a a $<0,05$; ** correlações significativas a a $<0,01$

Para identificar por que alguns estudantes escolhem 0 empreendedorismo enquanto outros não separou-se a amostra em dois grupos, conforme a resposta à pergunta "Dada a sua realidade atual (de conhecimento, econômica, aspirações, etc.), o que você planeja fazer após sua formatura?" Grupo 1 para as respostas: "continuar estudando", "trabalhar no(s) negócio(s) de sua família", "trabalhar como empregado no setor privado", "trabalhar como empregado no setor público", "fazer várias coisas (ou seja fazer mais de uma das alternativas anteriores)" e "não sabe". Grupo 2 para a resposta "montar o seu próprio negócio". Do total de 574 respostas válidas, apenas $32(5,6 \%)$ responderam que, considerando sua realidade, ainda assim pretendiam montar o seu próprio negócio após a formatura (Tabela 5). Quando os dados são analisados por semestre e por curso, observa-se que as escolhas quanto ao planejamento futuro não variam significativamente. Ou seja, as respostas dadas quanto ao planejamento futuro independem do semestre o qual o estudante está cursando (Teste do Q-quadrado com 8 graus de liberdade $=5,24 ; p>0,05$ ), bem como do curso de graduação (Teste do Q-quadrado com 5 graus de liberdade $=5,90$; $p>0,05)$.

Tabela 5: Planejamento profissional futuro conforme a realidade atual por semestre e por curso 
Mario Duarte Canever, Volnei Krause Kohls, Marcelo Lagemann, Paulo Rigatto Empreendedorismo: por que alguns estudantes e não outros escolhem ser empreendedores?

\begin{tabular}{|c|c|c|c|c|c|c|c|c|c|c|c|}
\hline \multirow{2}{*}{ Grupas } & & \multicolumn{9}{|c|}{ Semetre } & \multirow{2}{*}{ Total } \\
\hline & & 1 & 2 & 3 & 4 & 5 & 6 & 7 & $\mathrm{~B}$ & 9 & \\
\hline \multirow{3}{*}{1} & Respondentes & 71 & 45 & $\mathrm{BO}$ & 51 & 6.3 & 65 & 64 & 58 & 45 & 542 \\
\hline & \% dentro do qrupo 1. & 13,1 & 6,3 & 14,6 & 9,4 & 11,6 & 12,0 & 11,5 & 10,7 & 5,3 & 100,0 \\
\hline & \% dentre do semetre & 92,2 & 95.7 & 97,6 & 94,4 & 94,0 & 97,0 & 94,1 & 93,5 & 90,0 & 94,4 \\
\hline \multirow{3}{*}{2} & Respondentes & 6 & 2 & 2 & 3 & 4 & 2 & 4 & 4 & 5 & 32 \\
\hline & 9u dentro ds a rupe 2 & 18,8 & 6,3 & 6,3 & 9,4 & 12.5 & 6,3 & $12: 5$ & 12,5 & 15,6 & 100,0 \\
\hline & \% dentro do semetre & 7,8 & 4,3 & 2,4 & 5,6 & 6,0 & 3,0 & 5,9 & 6,5 & 10,0 & 5,6 \\
\hline \multicolumn{2}{|c|}{ Total de responden tes } & 77 & 47 & 82 & 54. & 6.7 & 67 & 6E: & 62 & 50 & $57-4$ \\
\hline & & \multicolumn{9}{|c|}{ Curss de gradusças } & \multirow{2}{*}{ Total } \\
\hline & & Agro & & let & Eco & & Am & Nut & & gnto & \\
\hline \multirow{3}{*}{1} & $R=$ pondentes & 128 & \multicolumn{2}{|c|}{118} & 45 & \multicolumn{2}{|c|}{89} & 45 & \multicolumn{2}{|c|}{117} & $5-42$ \\
\hline & \% dentro do grupo 1 & $2: 3,6$ & \multicolumn{2}{|c|}{21,8} & $\mathbf{B}, \mathbf{3}$ & \multicolumn{2}{|c|}{ \pm 6.4} & 8,3 & \multicolumn{2}{|c|}{21,6} & $\pm 00,0$ \\
\hline & of dentro do eurgs & 94,8 & \multicolumn{2}{|c|}{91,5} & 95,7 & \multicolumn{2}{|c|}{$97, \mathrm{~B}$} & 97,8 & \multicolumn{2}{|c|}{92,9} & 94,4 \\
\hline \multirow{3}{*}{2} & Respondentes & 7 & \multicolumn{2}{|c|}{11} & 2 & \multicolumn{2}{|c|}{2} & 1 & \multicolumn{2}{|c|}{9} & 32 \\
\hline & \% dentro do qrupo 2 & $2: 1,9$ & \multicolumn{2}{|c|}{34,4} & 6,3 & \multicolumn{2}{|c|}{6,3} & 3,1 & \multicolumn{2}{|c|}{$2 \mathrm{~B}_{,} 1$} & 100,0 \\
\hline & ob denitro do curso: & 5,2 & \multicolumn{2}{|c|}{8.5} & 4.3 & \multicolumn{2}{|c|}{2.2} & 2.2 & \multicolumn{2}{|c|}{7.1} & 5,6 \\
\hline \multicolumn{2}{|c|}{ Total derespondentes } & 135 & \multicolumn{2}{|c|}{179} & 47 & \multicolumn{2}{|c|}{91} & 46 & \multicolumn{2}{|c|}{126} & 574 \\
\hline
\end{tabular}

Agro $=$ Agronomia, Vet $=$ Veterinária, Eco $=$ Economia, Adm $=$ Administração, Nut $=$ Nutrição, Odonto $=$ Odontologia.

O Gráfico 2 ilustra detalhadamente o planejamento futuro por semestre. Em geral, uma menor proporção de estudantes dos semestres finais da graduação planeja continuar estudando ou fazer várias coisas após a formatura, quando comparados com os estudantes dos semestres iniciais. Ou seja, conforme passam os semestres, mais estudantes substituem as duas opções acima por trabalhar como empregado tanto no setor público quanto no privado, montar o seu próprio negócio ou ainda trabalhar no negócio da família. É saliente, ainda, o fato da proporção de estudantes que não sabem o que fazer no futuro ser baixo nos primeiros semestres, aumentar no terço mediano, e voltar a cair nos semestres finais.

Gráfico 2: O planejamento futuro ao longo dos semestres dos cursos de graduação

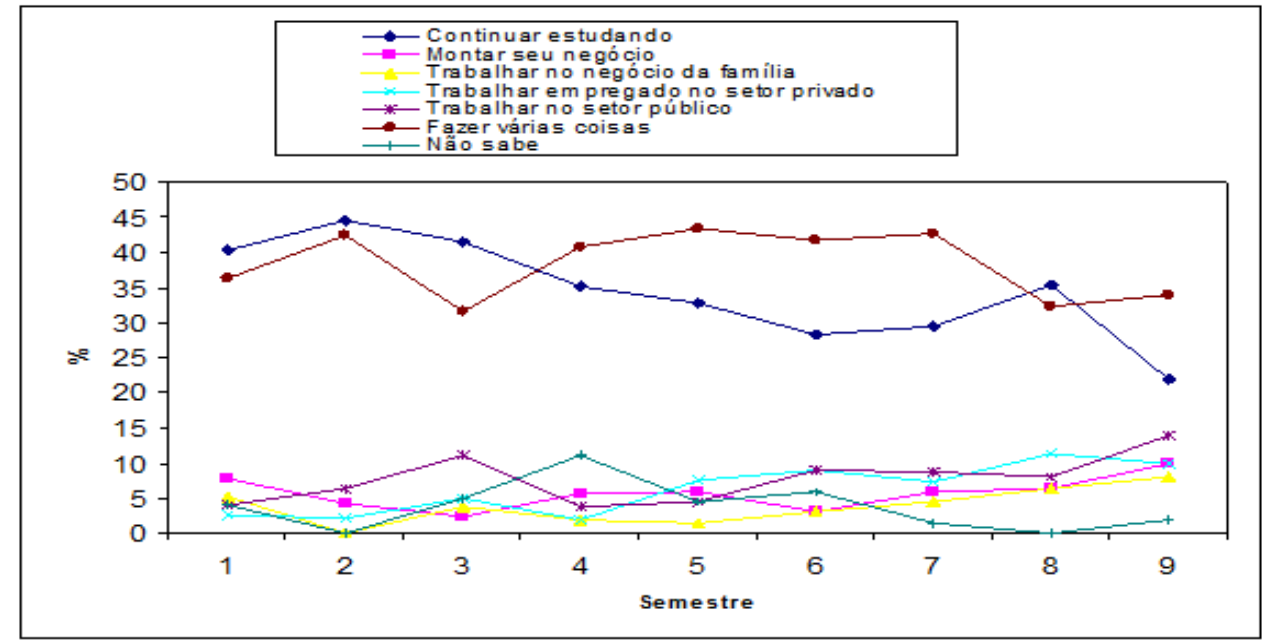

Estud. pesqui. psicol., Rio de Janeiro, v. 13, n. 1, p. 101-124, 2013. 
Para determinar a associação entre as variáveis sócio-econômicas e demográficas com o planejamento para o pós-formatura, foi realizada uma série de testes de Q-quadrado. Das cinco variáveis analisadas gênero, envolvimento de familiares com negócio próprio, tipo de escola onde realizou o ensino médio, renda familiar mensal e idade (acima e abaixo da média da amostra $=22,29$ anos) - apenas 0 gênero e a idade foram associadas significativamente com 0 planejamento futuro dos estudantes (Teste do Q-quadrado com 1 grau de liberdade $=10,590 ; p<0,001$ para o gênero e de 6,065; $\mathrm{p}<0,01$ para a idade). Os resultados mostram, portanto, que a tese de que os pais com negócio próprio (pais como modelos) e o nível da renda familiar (família como suporte) teorizada por De Wit e Van Winden (1989), de serem associadas com o planejamento de tornarse empreendedor não se verifica no caso dos estudantes universitários estudados aqui. Os dados mostram que o fato dos respondentes serem do sexo masculino e serem mais velhos tem uma influência significativa nas aspirações empreendedoras dos estudantes (Tabela 6).

Tabela 6: O planejamento futuro em relação a variáveis demográficas e socioeconômicas

\begin{tabular}{|c|c|c|c|c|}
\hline \multirow{2}{*}{$\begin{array}{l}\text { Variáveis sócio- } \\
\text { econßmicas = } \\
\text { demográficas }\end{array}$} & \multirow[b]{2}{*}{ Categorias } & \multicolumn{2}{|c|}{ Plarejamento para o pos formatura } & \multirow[b]{2}{*}{ Tota } \\
\hline & & Plareja empresnder & $\begin{array}{c}\text { demais } \\
\text { planglamentos }\end{array}$ & \\
\hline \multirow{3}{*}{ GQ̈nero } & Feminino & 7 & 279 & 286 \\
\hline & Masculino & 25 & 263 & $28 B$ \\
\hline & Total & 32 & 542 & 574 \\
\hline \multirow{4}{*}{$\begin{array}{l}\text { Onde cursou o } \\
\text { ensino médio }\end{array}$} & Escola Pública & 22 & 324 & 346 \\
\hline & Escola Partizular & B & 179 & 187 \\
\hline & Ambos & 1 & 14 & 15 \\
\hline & Total & 31 & 517 & 548 \\
\hline \multirow{3}{*}{$\begin{array}{l}\text { Algum familiar } \\
\text { com nagóio } \\
\text { proprio }\end{array}$} & Sim & 21 & 324 & 345 \\
\hline & Nas & 11 & 212 & 223 \\
\hline & Total & 32 & 536 & 568 \\
\hline \multirow{5}{*}{ Renda familiar } & $<R \$ 1.000,00$ & 5 & 93 & 98 \\
\hline & $d=R \$ 1.001,00=2.500,00$ & 10 & 209 & 219 \\
\hline & $d=R \$ 2.501,00=5000,00$ & 13 & 160 & 173 \\
\hline & $>R \$ 5.000,00$ & 2 & 66 & 68 \\
\hline & Total & 30 & 528 & 558 \\
\hline \multirow{3}{*}{$\begin{array}{l}\text { Categoria de } \\
\text { idade }\end{array}$} & < média de 22,29 anos & 14 & 353 & 367 \\
\hline & $>$ média de 22,29 anos & 18 & 188 & 206 \\
\hline & Total & 32 & 541 & 573 \\
\hline
\end{tabular}

Em relação aos fatores motivacionais não se observou diferença significativa entre os dois grupos, com excessão de ser independente expresso na frase "ser dono do próprio nariz" (Tabela 7). Mesmo que hipóteses estabelecessem a direção do efeito destas variáveis no planejamento futuro, o que permitiria usar o teste $t$ unicaudal, 
somente mais uma varíavel atitudinal "importância de ser um ótimo aluno" alcançaria significância ao nível de alpha de 0,10. Enfim, mesmo que as médias não sejam significativamente diferentes, parece que coerentemente com a literatura apresentada na seção 2, os estudantes que planejam empreender dão menos relevância para o reconhecimento social, para a importância de ser um ótimo aluno e acreditam menos que o curso de graduação vai oportunizar boa opção salarial.

A atitude em relação ao risco de falhar na vida profissional parece não ter efeito no planejamento futuro dos estudantes. De fato, uma análise mais aprofundada dos dados, com todas as categorias resultantes da pergunta sobre o planejamento futuro, dada a realidade atual dos estudantes revela que, mesmo com diferentes interesses profissionais, os estudantes apresentaram respostas muito similares a este fator. A média variou de 3,20 para aqueles que pretendiam trabalhar no(s) negócio(s) da família a 3,94 para os que pretendiam trabalhar empregados no setor privado. A análise de variância realizada nas médias dos grupos aceita a hipótese nula com um nível de significância de 0,38, a qual revela a inexistência de diferenças significativas entre os grupos.

Tabela 7: Fatores motivacionais e atidudinais entre os grupos

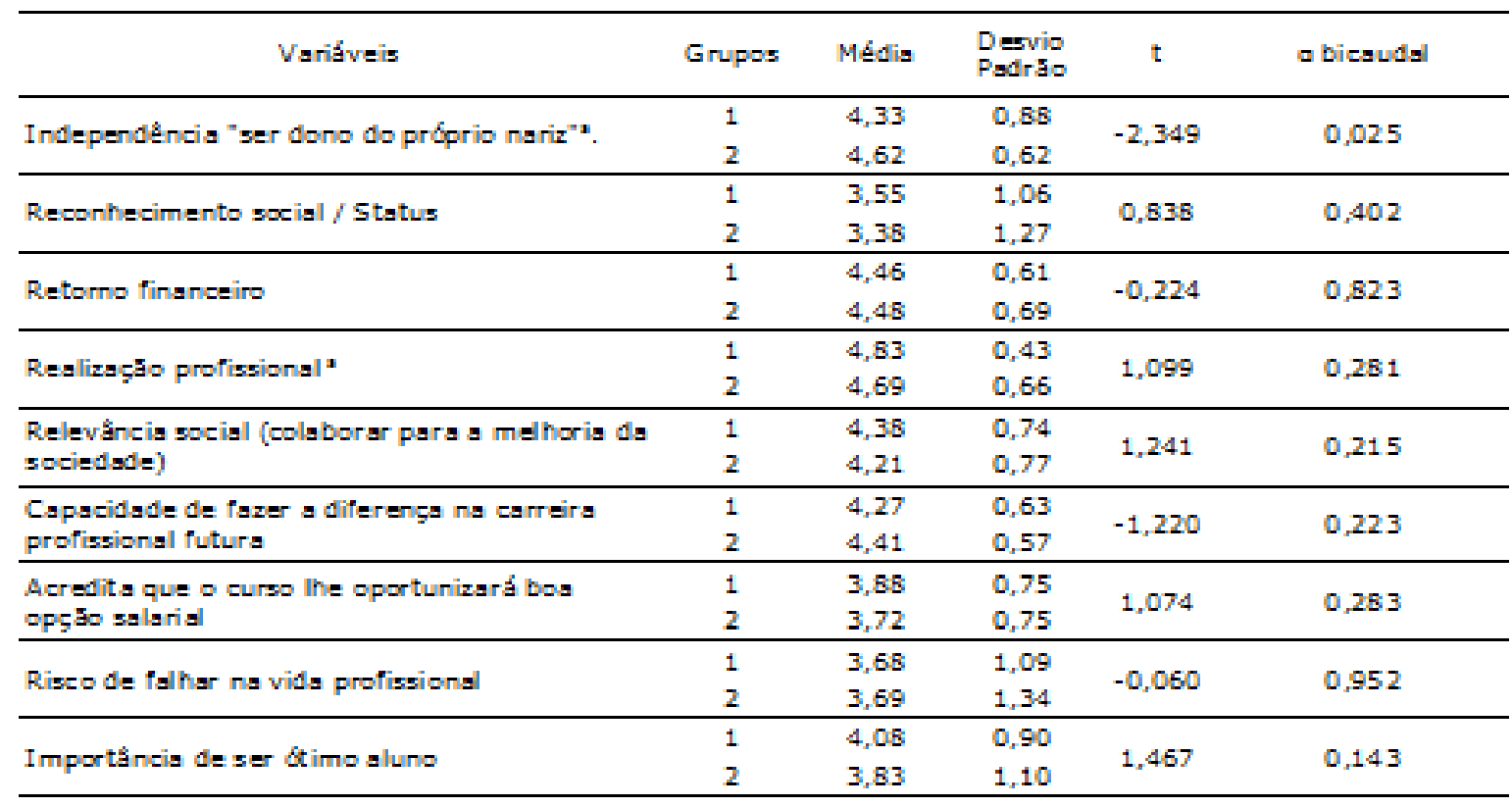

a Teste t para varianças não homogêneas entre os grupos.

Este resultado é surpreendente e pode ser uma das razões para o baixo nível de participação dos estudantes na criação de novos negócios. A média para a questão "O risco de falhar na vida profissional é uma preocupação para você?" foi de 3,67 (nada 
importante $=1$; muito importante $=5$ ), o que mostra uma atitude altamente avessa ao risco entre os estudantes universitários. Além disso, o escore para o risco é significativamente maior para as mulheres $(\bar{x}=3,84)$ do que para os homens $(\bar{x}=3,46), \mathrm{t}=3,99$ com 518 graus de liberdade e $p<0.001$. Deve ser observado ainda que a atitude de risco por parte do sexo masculino tende a ser mais extrema, isto é, uma maior proporção de homens tende a concordar em tomar risco, o que é exatamente o inverso entre as mulheres.

$O$ efeito de outros fatores na atitude de risco também foram baixos. O fato da famíla ter ou não um negócio próprio não é relacionado com a atitude de risco, e mesmo a importância de ser um ótimo aluno não é fortemente relacionada com risco (correlação bivariada $(r)=0,11 ; p<0,01)$. Finalmente, a atitude de risco é negativa e fracamente relacionada com o conhecimento para iniciar um novo negócio $(r=-0,09 ; p<0,05)$, e também com o conhecimento para gerenciar um negócio $(r=-06 ; p>0,05)$. Portanto, enquanto um melhor nível de conhecimento reduz um pouco a aversão ao risco, um alto nível de interesse ao empreendedorismo não encoraja os estudantes a tomarem maiores níveis de risco.

Finalmente, a Tabela 8 mostra o engajamento dos estudantes nas mais diversas atividades ao longo da vida universitária. Aqueles que planejam empreender, demostram estarem mais envolvidos com atividades fora da universidade, tendem a fazer várias coisas ao mesmo tempo e menor proporção deles dizem não terem nenhum envolvimento com atividades extra curriculares do que os que planejam não serem empreendedores.

Tabela 8: Envolvimento com atividades durante a graduação

\begin{tabular}{|c|c|c|}
\hline \multirow[b]{2}{*}{ Envolvimento em atividades durante a gradusçăo } & \multicolumn{2}{|c|}{ Planejamento futuro } \\
\hline & $\begin{array}{c}\text { Planejam empreander } \\
(\%)\end{array}$ & $\begin{array}{c}\text { Planejam fazer outras } \\
\text { coisas ( }(9)\end{array}$ \\
\hline Atividades acadûmicas na universidsde (bolss, estágios, ete) & 16,7 & 17,3 \\
\hline Estágios a trabalhos fora da universidade & 16,7 & 10,1 \\
\hline Movimento estudantil & 0,0 & 0,6 \\
\hline Cursos para desenvolver habilidades comportamentsis & 0,0 & 0,2 \\
\hline Cursos para desenvolver habilidades técnicas & 4,2 & 6,3 \\
\hline Trabslhos comunitários & 0,0 & 0,6 \\
\hline Nenhum envolvimento & 4,2 & 14,1 \\
\hline Faz váriss atividades (combinsçaso das atividades snteriores) & 58,3 & 50,8 \\
\hline
\end{tabular}

\section{Conclusões}


Neste artigo investigou-se o interesse dos estudantes de graduação no empreendedorismo e as razões que fazem alguns estudantes, e não outros, optarem por se tornarem empreendedores. Os resultados têm implicações relevantes para os pesquisadores, educadores universitários bem como para os formadores de políticas educacionais. Primeiramente, o interesse no empreendedorismo por parte dos estudantes universitários é alto e espelha os resultados observados em outros países ocidentais (KOLVEREID, 1996) e asiáticos (WANG e WONG, 2004). Muitos dos estudantes mostraramse interessados em montar o seu próprio negócio no futuro $(29,8 \%$ disseram ter muito interesse em empreender em uma escala variando de 1-nenhum interesse a 5-muito interesse) e muitos dizem estar adequadamente preparados para a empreitada (aproximadamente $40 \%$ ). Tal resultado é controverso, no entanto. Se, a honestidade das respostas é inquestionável, pode-se inferir que os estudantes estão positivamente viesados quanto a real capacidade de montarem e gerirem um negócio. Isto pode ocorrer pela inexperiência e falta de conhecimento das dificuldades de ser um empreendedor. Exceto o curso de administração de empresas, nenhum outro oferece regularmente em seu currículo disciplinas na área da gestão de negócios, gestão de pessoas e empreendedorismo, então se conclui que na média $o$ nível das habilidades empreendedoras e de gestão entre os estudantes é baixo. Além dos fatores acima, a razão para o otimismo pode estar associada com o momento positivo da economia brasileira e de exemplos bem sucedidos de colegas empreendedores, o que os faz negligenciarem a falta de conhecimento para iniciarem e gerenciarem um negócio. A educação universitária necessita, portanto, atentar cuidadosamente para o fato de estar criando falsas expectativas quanto às reais possibilidades dos estudantes de serem empreendedores e estarem capacitados a empreender. Tal fato se torna ainda mais importante e relevante para o planejamento educacional das universidades na medida em que os resultados mostram que os estudantes não são preparados para arriscarem-se para realizarem os seus sonhos profissionais.

Segundo, o interesse dos estudantes em empreender não diminui do início ao final do curso de graduação. O nível de interesse apresentase suavemente decrescente no segundo terço da graduação, mas torna-se novamente crescente no estágio final dos cursos. Tal fato relembra as fases da vida universitária apresentada por Lassance (1997), porém estas fases não se fazem suficientes para alterarem o interesse dos alunos no empreendedorismo. Coerentemente com a relativa estabilidade do interesse em empreender ao longo da graduação, não foram observadas tendências (nem de queda e nem de aumento) da relação fatores motivacionais e da atitude com o interesse em empreender. Mais surpreendente, no entanto, foi 0 
baixo nível de associação observado entre estas variáveis e o interesse em empreender, o que levanta a questão se a educação universitária está preparando os estudantes para terem espírito crítico, discernimento e maturidade para avaliarem suas reais condições empreendedoras. Outra questão também a ser estudada é se a educação universitária está oportunizando aos alunos conhecimentos que ajudem na construção de uma personalidade empreendedora. A julgar pelos dados desta pesquisa, existe um vácuo entre o desejo de ser empreendedor e as características que perfazem um indivíduo empreendedor que contradiz importantes estudos anteriores (LOCKE, 2000; MITCHEL, et al., 2007).

Terceiro, coerente com referências internacionais (BRENNER, PRINGLE e GREENHAUS, 1991), somente 5,6\% dos estudantes realmente planejam ser empreendedores quando são levados a considerar suas limitações e condições atuais. O gênero dos estudantes (masculino) e a idade (mais velhos) estão associados significativamente com o planejamento de iniciar o seu próprio negócio após a formatura, enquanto que as demais variáveis sócioeconômicas e demográficas não apresentam efeitos nesta escolha. As análises revelam também que as estudantes planejam menos se tornarem empreendedoras, não porque acreditam menos na capacidade de fazerem a diferença, mas por serem mais avessas ao risco e por terem menor nível de conhecimento para iniciarem e gerenciarem um novo negócio. Possivelmente a diferença entre gêneros pode estar associada ao papel social atribuído as mulheres. Ademais, os resultados mostram que o campo do empreendedorismo é dominado por indivíduos que são motivados pela independência, pela possibilidade de serem livres e "donos dos seus próprios narizes".

Portanto, os resultados nos remetem a várias implicações com o objetivo de desenvolver uma educação universitária empreendedora. Como o interesse por parte dos estudantes no empreendedorismo é alto, há um enorme potencial para a oferta de cursos sobre este tema, principalmente para os estudantes das áreas técnicas (que não visam à formação em administração e, possivelmente, economia). Estes cursos podem ser orientados às mulheres, visto que elas apresentaram menor nível de conhecimento para lidarem com a criação e gestão de um novo negócio e são mais avessas ao risco. Obviamente, os educadores devem também empreender esforços para que haja mudanças da mentalidade tradicional que reza que o mundo do empreendedorismo é essencialmente um mundo masculino.

Os resultados também sugerem que os formuladores de políticas educacionais devem focar em meios para mitigar os efeitos de uma educação alienante que contribui para o insucesso dos futuros empreendedores. Ou seja, é necessário incentivar o 
empreendedorismo nas universidades, mas de forma responsável para que os alunos não sejam levados a pensar que fazendo um curso universitário nos moldes atuais estarão prontos para empreender. Potencialmente, ao deixar a situação como está hoje, o ensino universitário estará contribuindo para a elevação da taxa de mortalidade empresarial, que no Brasil já é uma das mais altas do mundo.

Uma educação empreendedora pode ter um papel relevante em atenuar a aversão ao risco dos estudantes. As universidades podem criar cursos específicos para que os estudantes aprendam a tomar riscos calculados através de exemplos (empreendedores de sucesso) e para analisarem estudos de casos locais e/ou regionais de modo a elevar o nível de contato e conhecimento das oportunidades de começar o seu próprio negócio.

Finalmente, pesquisas futuras poderão estender a presente pesquisa em várias direções. Uma direção seria a de replicar o mesmo estudo com estudantes de outras faculdades e de outras universidades públicas e privadas. No presente estudo somente três áreas do conhecimento foram amostradas: ciências agrárias, ciências da saúde e ciências sociais aplicadas. Poder-se-ia também aplicar o mesmo estudo com estudantes de pós-graduação (stricto sensu e lato sensu) e estudantes de instituições politécnicas (secundárias e terciárias) para comparar o interesse no empreendedorismo. Outra avenida promissora de investigação refere-se ao exame das relações entre conhecimento e interesse em empreender, fatores motivacionais e cognitivos que influenciam nas escolhas profissionais e o impacto do viés positivo na ação empreendedora futura dos estudantes. Poderse-ia também refazer o estudo utilizando-se de indicadores múltiplos para os constructos motivacionais e atitudinais utilizados nesta pesquisa.

\section{Referências}

ALSTETE, J. W. On becoming an entrepreneur: an evolving typology. International Journal of Entrepreneurial Behaviour \& Research, Bingley, Gran Bretanha, v. 8, n. 4, p. 222-34, 2002. AUDRETSCH, D. B., KEILBACH, M. Entrepreneurship capital and economic performance. Regional Studies, Londres, v. 38, n. 8, p. 949-959, 2004.

BARON, R. The cognitive perspective: a valuable tool for answering entrepreneurship's basic "why" questions. Journal of Business Venturing, Bloomington, EUA, v. 19, p. 221-239, 2004.

BAUM, J. R. The relationship of traits, competencies, motivation, strategy and structure to venture growth. 1994. 
259 p. Tese (Doutorado em Business) - University of Meryland, MD, USA, 1994.

BRENNER, O. C.; PRINGLE CH., D.; GREENHAUS, H. Perceived fulfillment of organizational employment versus entrepreneurship: work values and career intentions of business college graduates. J ournal of Small Business Management, Malden, EUA, v. 29, n. 3, p. 62-74, 1991.

BROWN, R. Encouraging enterprise: Britain's Graduate Enterprise Program. Journal of Small Business Management, Malden, EUA, v. 28, n. 4, p. 71-77, 1990.

CARRER, C. C., PLONSKI, G. A., CARRER, C. R. O., OliVEIRA, C. E. L. Innovation and entrepreneurship in scientific research. Revista Brasileira de Zootecnia, Viçosa, v. 39, p. 17-25, 2010.

CRANT, J. M. The proactive personality scale as a predictor of entrepreneurial intentions. Journal of Small Business Management,Malden, EUA, v. 34, n. 3, p. 42-49, 1996.

CROMIE, S. Assessing entrepreneurial inclinations: some approaches empirical evidence. European Journal of Work and Organizational Psychology, Bruxelas, v. 9, n. 1, p. 7-30, 2000.

DE WIT, G.; VAN WINDEN, F.A. An empirical analysis of self employment in the Netherlands. Small Business Economics, Dordrecht, v. 1, n. 4, p. 263-272, 1989.

DOLABELA, F. O segredo de Luísa. 14.ed. São Paulo: Cultura, 2005. DOLTON, P.J.; MAKEPEACE, G.H. Self-employment among graduates. Bulletin of Economic Research, Malden, EUA, v. 42, n. 1, p. 3553, 1990.

FRY, F. L. Entrepreneurship: a planning approach. MinneapolisSt. Paul, MN: West Publishing, 1993.

GHAZALI, A.; GHOSH, B. C.; TAY, R. S. T. The determinants of selfemployment choice among university graduates in Singapore. I nternational J ournal of Management, Dorset, Inglaterra, v. 12, n. 1, p. 26-35, 1995.

GIBB, A. Small business development in Central and Eastern Europe - opportunity for a rethink? Journal of Business Venturing, Bloomington, EUA, v. 8, p. 461-86, 1993.

GORMAN, G.; HANLON, D.; KING, W. Some research perspectives on entrepreneurship education and education for small business management: a ten-year literature review. International Small Business J ournal, Thousand Oaks, v. 15, n. 3, p. 56-77, 1997.

GUROL, Y.; ATSAN, N. Entrepreneurial characteristics amongst university students: Some insights for entrepreneurship education and training in Turkey. Education + Training, Malden, EUA, v. 48, n. 1, p. 25-38, 2006.

HYTTI, U.; O'GORMAN, C. What is 'enterprise education'? An analysis of the objectives and methods of enterprise education programmes in 
four European countries. Education \& Training, Malden, EUA ,v. 46, n. 1, p. 11-23, 2004.

IPIRANGA, A. S. R., FREITAS, A. A. F. DE, PAIVA, T. A. O empreendedorismo acadêmico no contexto da interação universidade - empresa - governo. Cadernos EBAPE.BR., Rio de Janeiro, v. 8, n. 4, p. 676-693, 2010.

JACK, S. L.; ANDERSON, A. R. Entrepreneurship education within the enterprise culture. International Journal of Entrepreneurial Behaviour \& Research, Bingley, Gran Bretanha, v. 5, n. 3, p. 110125, 1999.

JONES, C.; ENGLISH, J. A contemporary approach to entrepreneurship education. Education \& Training, Malden, EUA, v. 46, n. 8/9, p. 416-23, 2004.

KIRBY, D.A. Entrepreneurship education: can business schools meet the challenge. Education \& Training, Malden, EUA, v. 46, p. 510519, 2004.

$\mathrm{KOH}, \mathrm{H} . \mathrm{C}$. Testing hypotheses of entrepreneurial characteristics. J ournal of Managerial Psychology, Bingley, Gran Bretanha, v. 11, n. 3, p. 12-25, 1996.

KOLVEREID L. Organisational employment versus self-employment: Reasons for career choice intentions. Entrepreneurship Theory and Practice, Waco, EUA, v.20, n. 3, p.23-31, 1996.

KOURILSKY, M.L.; WALSTAD, W.B. Entrepreneurship and female youth: knowledge, attitudes, gender differences, and educational practices. Journal of Business Venturing, Bloomington, EUA, v. 13, n. 1, p. 77-88, 1998.

LASSANCE, M. C. P. A orientação profissional e a globalização da economia. Revista da ABOP,São Paulo, v. 1, p. 71-80, 1997.

LEMOS, C. G.; BUENO, J. M. H.; DA SILVA, P. L.; GENICOLO, V. C. Referenciais de carreira e identidade profissional em estudantes universitários. Psicologia Ciência e Profissão, Brasília, v. 27, n. 2, p. 208-223, 2007.

LOCKE, E. A. Motivation, cognition and action: an analysis of studies of task goals and knowledge. Applied Psychology: An International Review, Weinheim, Alemanha, v. 49, p. 408-429, 2000.

LOUW L.; EEDEN, S. M.; BOSCH, J. K; VENTER, D. J. L. Entrepreneurial traits of undergraduate students selected South African tertiary institutions. Management Dynamics, Johannesburg, v. 6, n.4, p.73-90, 2003.

MATTHEWS, C. H.; MOSER, S. B. A longitudinal investigation of the impact of family background and gender on interest in small firm ownership. J ournal of Small Business Management, Malden, EUA, v. 34, n. 2, p. 29-43, 1996.

MC CLELLAND, D. C. The Achieving Society. Princeton, NJ: Van n.strand, 1961. 
MCMULLEN, J. S.; MORSE, E. A.; SMITH, J. B. The central question in entrepreneurial cognition research 2007. Entrepreneurship Theory \& Practice, Waco, EUA, p. 1-27, Jan. 2007.

MITCHELL, R. K.; BUSENITZ, L. W.; BIRD, B.; GAGLIO, C. M.; MUELLER, S. L.; THOMAS, A. S. Culture and entrepreneurial potential: a nine country study of locus of control and innovativeness. J ournal of Business Venturing, Bloomington, EUA, v. 16, p. 51-75, 2000.

PALICH, L. E.; BAGBY, D. R. Using cognitive theory to explain entrepreneurial risk-taking: challenging conventional wisdom. J ournal of Business Venturing, Bloomington, EUA ,v. 10, p. 425438. 1995.

PROVINCIALI, v. L. N.; SARAIVA, L. A. S.; MESQUITA, H. T.; CAMPOS, L. O. B. N. A graduação em administração sob a ótica discente: um estudo comparativo em instituições de ensino superior de Sergipe. Caderno de Pesquisas em Administração, São Paulo, v. 12, n. 2, p. 19-36, abril/junho 2005.

RONCON, P. F., MUNHOZ, S. Estudantes de enfermagem têm perfil empreendedor? Revista Brasileira de Enfermagem, Brasília, v. 62, n. 5, p. 695-700, 2009.

SARASVATHY, D.; SIMON, H.; LAVE, L. Perceiving and managing business risks: differences between entrepreneurs and bankers. Journal of Economic Behavior and Organization, Philadelphia, v. 33, p. 207-225, 1998.

SCHLEMM, M. M.; PASSOS, C. A. K.; FELIX, J. C.; GRECO, S. M. S. S.; BASTOS JÚNIOR, P. A.; MACHADO, J. P.; KRUPA, S. Empreendedorismo - Brasil: 2006. Curitiba : IBQP, 2007. SCOTT, M.G.; TWOMEY, D.F. The long-term supply of entrepreneurs: students' career aspirations in relation to entrepreneurship. J ournal of Small Business Management, Malden, EUA, v. 26, n. 4, p. 513, 1988.

SHANE, S.; LOCKE, E. A.; COLLINS, C. J. Entrepreneurial motivation. Human Resource Management Review, Philadelphia, v. 13, p. 257-279, 2003.

STEWART, W.H. JR; WATSON, W.; CARLAND, J.C.; CARLAND, J.W. A proclivity for entrepreneurship: a comparison of entrepreneurs, small business owners, and corporate managers. Journal of Business Venturing,Bloomington, EUA, v. 14, n. 2, p. 189-214, 1999.

TIMMONS, J.A. New venture creation: entrepreneurship for the 21st Century. Boston: Irwin, 1994.

VAN DE VEN, A.H.; SCHROEDER, D.M. Designing new business startups: entrepreneurial, organizational, and ecological considerations. J ournal of Management, Mississippe, v. 10, n. 1, p. 87-107, 1984. 
VAN STEL, A. J.; STOREY, D. J. The Link between firm births and job creation: Is there a Upas tree effect? Regional Studies, Londres, $v$. 38, n. 8, p.893-909. 2004.

WANG, K. W.; WONG, P-K. Entrepreneurial interest of university students in Singapore. Technovation, Philadelphia, v. 24, n. 1, p. 163-172, 2004.

\section{Endereço para correspondência Mario Duarte Canever*}

Departamento de Ciências Sociais Agrárias, Universidade Federal de Pelotas, C. P. 354, 96010-900 Pelotas, Rio Grande do Sul, Brasil

Endereço eletrônico: canever@ufpel.edu.br

\section{Volnei Krause Kohls**}

Departamento de Ciências Sociais Agrárias, Universidade Federal de Pelotas, C. P. 354, 96010-900 Pelotas, Rio Grande do Sul, Brasil

Endereço eletrônico: vkkohls2002@yahoo.com.br

\section{Marcelo Lagemann***}

Connectere AgroGestão, Rua Marcílio Dias, 2946 - Sala 202 , CEP 96.020-480 Pelotas, Rio Grande do Sul, Brasil

Endereço eletrônico: marcelo.lagemann@gmail.com

\section{Paulo Rigatto****}

Departamento de Ciências Sociais Agrárias, Universidade Federal de Pelotas, C. P. 354, 96010-900 Pelotas, Rio Grande do Sul, Brasil

Endereço eletrônico: prof_rigatto@yahoo.com

Recebido em: 13/06/2011

Reformulado em: 29/08/2011

Aceito para publicação em: 15/09/2011

Acompanhamento do processo editorial: Deise Maria Leal Fernandes Mendes

\section{Notas}

* Professor da Universidade Federal de Pelotas.

** Professor da Universidade Federal de Pelotas.

*** Economista e Engenheiro Agrônomo.

$* * * *$ Professor Universidade Federal de Pelotas.

${ }^{1}$ Consulta realizada no endereço: http://capesdw.capes.gov.br/capesdw/Teses.do , no dia 08 de agosto de 2011. A busca foi realizada utilizando-se as seguintes palavras-chaves: Empreendedorismo, Universidade, Estudantes.

${ }^{2}$ Global Entrepreneurship Monitor 